\title{
Efficient bioproduction of 5-aminolevulinic acid, a promising biostimulant and nutrient, from renewable bioresources by engineered Corynebacterium glutamicum
}

Jiuzhou Chen ${ }^{\dagger}$, Yu Wang ${ }^{\dagger} \mathbb{D}$, Xuan Guo, Deming Rao, Wenjuan Zhou, Ping Zheng ${ }^{*} \mathbb{D}$, Jibin Sun ${ }^{*}$ and Yanhe Ma

\begin{abstract}
Background: 5-Aminolevulinic acid (5-ALA) is a promising biostimulant, feed nutrient, and photodynamic drug with wide applications in modern agriculture and therapy. Considering the complexity and low yield of chemical synthesis methods, bioproduction of 5-ALA has drawn intensive attention recently. However, the present bioproduction processes use refined glucose as the main carbon source and the production level still needs further enhancement.

Results: To lay a solid technological foundation for large-scale commercialized bioproduction of 5-ALA, an industrial workhorse Corynebacterium glutamicum was metabolically engineered for high-level 5-ALA biosynthesis from cheap renewable bioresources. After evaluation of 5-ALA synthetases from different sources, the 5-ALA biosynthetic pathway and anaplerotic pathway were rebalanced by regulating intracellular activities of 5-ALA synthetase and phosphoenolpyruvate carboxylase. The engineered biocatalyst produced $5.5 \mathrm{~g} / \mathrm{L} 5$-ALA in shake flasks and $16.3 \mathrm{~g} / \mathrm{L}$ in 5-L bioreactors with a one-step fermentation process from glucose. To lower the cost of feedstock, cheap raw materials were used to replace glucose. Enzymatically hydrolyzed cassava bagasse was proven to be a perfect alternative to refined sugars since the final 5-ALA titer further increased to $18.5 \mathrm{~g} / \mathrm{L}$. Use of corn starch hydrolysate resulted in a similar 5-ALA production level $(16.0 \mathrm{~g} / \mathrm{L})$ with glucose, whereas use of beet molasses caused seriously inhibition. The results obtained here represent a new record of 5-ALA bioproduction. It is estimated that replacing glucose with cassava bagasse will reduce the carbon source cost by $90.1 \%$.
\end{abstract}

Conclusions: The high-level biosynthesis of 5-ALA from cheap bioresources will brighten the prospects for industrialization of this sustainable and environment-friendly process. The strategy for balancing metabolic flux developed in this study can also be used for improving the bioproduction of other value-added chemicals.

Keywords: 5-Aminolevulinic acid, Renewable bioresource, Cassava bagasse, Corynebacterium glutamicum, Metabolic engineering

*Correspondence: zheng_p@tib.cas.cn; sunjibin@tib.cas.cn †Jiuzhou Chen and Yu Wang contributed equally to this work

Key Laboratory of Systems Microbial Biotechnology, Tianjin Institute of Industrial Biotechnology, Chinese Academy of Sciences, Tianjin 300308, China

\begin{abstract}
Background
5-Aminolevulinic acid (5-ALA), a non-proteingenic amino acid that widely exists in microbe, plant and animal cells, is a common precursor of tetrapyrrole compounds, such as heme, porphyrin, chlorophyll, and vitamin $B_{12}$. Because of the critical roles of tetrapyrrole compounds in regulating cell metabolism and growth, 5-ALA has gained increasing attention in the fields of
\end{abstract}

(c) The Author(s) 2020. This article is licensed under a Creative Commons Attribution 4.0 International License, which permits use, sharing, adaptation, distribution and reproduction in any medium or format, as long as you give appropriate credit to the original author(s) and the source, provide a link to the Creative Commons licence, and indicate if changes were made. The images or other third party material in this article are included in the article's Creative Commons licence, unless indicated otherwise in a credit line to the material. If material is not included in the article's Creative Commons licence and your intended use is not permitted by statutory regulation or exceeds the permitted use, you will need to obtain permission directly from the copyright holder. To view a copy of this licence, visit http://creativeco mmons.org/licenses/by/4.0/. The Creative Commons Public Domain Dedication waiver (http://creativecommons.org/publicdomain/ zero/1.0/) applies to the data made available in this article, unless otherwise stated in a credit line to the data. 
medicine, agriculture and livestock [1,2]. As a new generation of photosensitizer, 5-ALA has displayed wide applications in photodynamic diagnosis and therapy for various cancers and many skin diseases [3]. In agriculture, exogenous supplement with 5-ALA could effectively increase intracellular chlorophyll or heme levels in crop, livestock, and poultry. Therefore, 5-ALA can be used as a plant growth regulator to promote the yield and resist the harmful effects caused by various abiotic stresses [4]. 5-ALA can also be used as feed additives to enhance ATP production and immune response, leading to improved growth performance of chicken, pig, white shrimp, etc. [5-7]. Therefore, 5-ALA has been considered as a promising biostimulant for crop production and a feed nutrient for livestock breeding. It is estimated that the global market size of 5-ALA will reach US $\$ 110$ million by 2024 , from US\$ 86 million in 2019 [8].

Chemical synthesis is the primary method for industrial production of 5-ALA. Six chemically synthetic methods have been reported, whereas the complicated reaction and purification steps and low yield cause the high price of 5-ALA, which seriously limits its widespread use in agriculture [1]. Bioproduction of 5-ALA holds the potential to simplify the production process and lower the cost, and thus has received growing attention recently $[9,10]$. Although some algae and photosynthetic bacteria are capable to synthesize 5-ALA naturally, the production levels are not satisfactory and these microorganisms are usually difficult to engineer $[11,12]$. With the development of metabolic engineering and synthetic biology, intensive studies have concentrated on engineering platform microorganisms such as Escherichia coli and Corynebacterium glutamicum for 5-ALA bioproduction. A native C5 pathway that converts glutamate to 5-ALA via three enzymatic reactions exists in both $E$. coli and C. glutamicum [13]. By strengthening this biosynthetic pathway, 5-ALA production was achieved [14-20], but the highest titer and productivity were only $5.25 \mathrm{~g} / \mathrm{L}$ and $0.16 \mathrm{~g} / \mathrm{L} \mathrm{h}$, respectively [20]. To improve the 5-ALA production level, the exogenous C4 pathway for 5-ALA biosynthesis originated from photosynthetic bacteria was introduced into E. coli and C. glutamicum by expressing the 5-ALA synthetase (ALAS) catalyzing the condensation of succinyl-CoA and glycine to 5-ALA. Several strategies have been applied to further enforce the $\mathrm{C} 4$ biosynthetic route, such as enzyme screening [21-26], pathway engineering [27-31], tolerance engineering [32], and fermentation process optimization $[27,33]$. By reinforcing the native antioxidant defense system in an ALAS-expressing E. coli strain to combat with the reactive oxygen species generated by 5-ALA, Zhu et al. obtained the highest 5-ALA titer ( $11.5 \mathrm{~g} / \mathrm{L})$ of one-step fermentation [32]. Yang et al. constructed a
5-ALA producing C. glutamicum by expressing a codonoptimized ALAS from Rhodobacter capsulatus and deactivating the succinyl-CoA synthetase. By separating the growth and production phases, the engineered strain produced $14.7 \mathrm{~g} / \mathrm{L}$ 5-ALA [27]. However, the two-step fermentation strategy consisting of cultivating, collecting, and resuspending cells in a new buffer may be challenging for large-scale production.

So far, all the reported 5-ALA bioproduction processes rely on using glucose as the main carbon source (Table 1). Based on an economic analysis of a 10,000 tons pilot scale 5-ALA bioproduction process, we estimate that glucose cost accounts for approximately $12.5 \%$ of the total cost. To popularize application of 5-ALA in agriculture, further cost reduction is required. Therefore, cheap raw materials, such as molasses, cassava bagasse and woody biomass, are preferred to replace refined sugars. Although such cheap bioresources have been used for the bioproduction of several chemicals and biofuels [34-36], they have not been explored for 5-ALA production so far. Moreover, improving the conversion yield of the carbon source to 5-ALA and the final titer by metabolic engineering is also favorable for reducing the production cost of 5-ALA.

In this work, a superior 5-ALA producer was constructed based on C. glutamicum by screening ALAS candidates and balancing precursor supply and 5-ALA biosynthesis via regulating intracellular enzyme activities (Fig. 1). By this means, $16.3 \mathrm{~g} / \mathrm{L}$ 5-ALA was produced from glucose and glycine using a one-step fermentation. To further decrease the cost of feedstock, different cheap carbon sources, including cassava bagasse, corn starch, and beet molasses, were used to replace glucose. The highest 5-ALA titer $(18.5 \mathrm{~g} / \mathrm{L})$ was obtained using enzymatically hydrolyzed cassava bagasse. The metabolic balance strategy developed here can also be applied for improving the bioproduction of other value-added chemicals. The high-level biosynthesis of 5-ALA from cheap bioresources represents a crucial step in industrialization of 5-ALA bioproduction.

\section{Results and discussion}

\section{ALAS screening for 5-ALA production in C. glutamicum}

Since ALAS is an essential enzyme for 5-ALA production via C4 pathway and it is absent from C. glutamicum, introduction of a heterogeneous ALAS is required (Fig. 1). We previously identified two ALASs with superior activities, RpHemA and RpHemO, from Rhodopseudomonas palustris ATCC 17001 [25]. They were expressed via plasmid under the control of isopropyl- $\beta$ D-thiogalactopyranoside (IPTG)-inducible promoter $P_{t r c}$ and evaluated for 5-ALA production in C. glutamicum, together with another reported ALAS from Rhodobacter 
Table 1 Bioproduction of 5-ALA by engineered strains via C4 biosynthetic pathway from different substrates

\begin{tabular}{|c|c|c|c|c|}
\hline Strain and strategy & Main substrates & Titer $(\mathbf{g} / \mathbf{L})$ & $\begin{array}{l}\text { Productivity } \\
\text { (g/L h) }\end{array}$ & Reference \\
\hline \multicolumn{5}{|l|}{ E. coli } \\
\hline Overexpression of hemA from $R$. sphaeroides & Succinate, glycine & 5.2 & 0.43 & [21] \\
\hline Overexpression of hemA from R. palustris KUGB306 & Glucose, succinate, glycine & 5.2 & 0.32 & [23] \\
\hline Overexpression of hemA from R. sphaeroides 2.4 .1 & Glucose, succinate, glycine & 6.6 & 0.24 & [22] \\
\hline Overexpression of hemA from Agrobacterium radiobacter zju-0121 & Glucose, succinate, glycine, xylose & 7.3 & 0.24 & [24] \\
\hline Overexpression of hemO from R. palustris ATCC 17001 & Glucose, succinate, glycine & 6.3 & 0.26 & [25] \\
\hline $\begin{array}{l}\text { Overexpression of hemA from A. radiobacter zju-0121, short-term dis- } \\
\text { solved oxygen shock }\end{array}$ & Glucose, succinate, glycine & 9.4 & 0.43 & [33] \\
\hline Overexpression of hemA from $R$. capsulatus & Glycerol, succinate, glycine & 8.8 & 0.24 & {$[26]$} \\
\hline $\begin{array}{l}\text { Overexpression of hemA from } R \text {. capsulatus, pathway optimization for } \\
\text { CoA and precursor biosynthesis, downregulation of hemB }\end{array}$ & Glucose & 2.8 & 0.06 & {$[29]$} \\
\hline \multicolumn{5}{|l|}{ C. glutamicum } \\
\hline $\begin{array}{l}\text { Overexpression of hemA from } R \text {. sphaeroides, native ppc and } r \text { th } A \text { from } \\
\text { E. coli, deletion of } I d h A, p q o, c a t, p t a, a c k A \text { and } p b p 1 b\end{array}$ & Glucose, glycine & 7.5 & 0.23 & {$[28]$} \\
\hline Overexpression of hemA from R. capsulatus SB1003, deletion of sucCD & Glucose, glycine & 7.6 & 0.095 & {$[27]$} \\
\hline $\begin{array}{l}\text { Overexpression of hemA from R. capsulatus SB1003 and rhtA from E. } \\
\text { coli, deletion of sucCD }\end{array}$ & Glucose, glycine & $14.7^{\mathrm{a}}$ & $0.92^{\mathrm{a}}$ & \\
\hline \multirow{2}{*}{$\begin{array}{l}\text { Moderate overexpression of hemA from R. palustris ATCC } 17,001 \text { and } \\
\text { native ppc to balance 5-ALA biosynthetic and anaplerotic pathways }\end{array}$} & Glucose, glycine & 16.3 & 0.42 & \multirow[t]{2}{*}{ This study } \\
\hline & Cassava bagasse hydrolysate, glycine & 18.5 & 0.47 & \\
\hline
\end{tabular}

a A two-stage fermentation was employed. The cultivation time of the first step for cell growth was not reported in that study, and thus the productivity of the second step for 5-ALA production was shown

sphaeroides (RsHemA). C. glutamicum strain CA expressing RpHemA showed the highest ALAS activity in crude extract $(2.6 \mu \mathrm{mol} / \mathrm{L} \mathrm{min})$, followed by strains expressing RpHemO (2.2 $\mu \mathrm{mol} / \mathrm{L} \mathrm{min})$ and RsHemA $(1.3 \mu \mathrm{mol} / \mathrm{L} \mathrm{min})$ (Fig. 2). The 5-ALA titers were in line with the trend of ALAS activity. Compared with the other two ALASs, RpHemA was the best candidate for 5-ALA production in C. glutamicum, and the 5-ALA titer reached to $3.8 \mathrm{~g} / \mathrm{L}$, which was $15.2 \%$ and $18.9 \%$ higher than those produced by strains expressing RpHemO and RsHemA, respectively. These data indicated that 5-ALA production was closely related to the intracellular ALAS activity.

\section{Optimizing ALAS expression for enhanced 5-ALA production via ribosome binding site (RBS) engineering}

It is speculated that optimizing intracellular ALAS activity can further improve 5-ALA biosynthesis. Firstly, two native strong constitutive promoters $P_{\text {tuf }}$ and $P_{\text {sod }}$ [37] were first used to replace the IPTG-inducible one to regulate transcription of ALAS encoding gene. However, promoter replacement led to decreased intracellular ALAS activity and consequently decreased 5-ALA titer (Fig. 2), which were consistent with the fact that these two constitutive promoters exhibit lower activities relative to IPTG-inducible ones [37]. We then applied RBS engineering to fine-tune the translation level of ALAS and increase intracellular ALAS activity. Four RBSs
(RBS-2, AAAGGAGGTTGTC; RBS-3, AAAGGAGCG GTCC; RBS-4, AAAGGAGGATTAG; RBS-5, AAAGGA GTTGCTT) with relatively high translational activities were selected from previously constructed libraries [38] to replace the original RBS of ALAS encoding gene in strain CA (RBS-1, AAGGAGATATAGAT) and produced four recombinant strains designated as CA1, CA2, CA3, and CA4. All the four engineered strains exhibited increased ALAS activity in crude extract, and the highest activity reached $4.8 \mu \mathrm{mol} / \mathrm{L}$ min in strain CA4, nearly twice as much as that of strain CA (Fig. 3a). With the increase of intracellular ALAS activity, the 5-ALA production level ascended first and then descended. The highest 5-ALA titer $(4.4 \mathrm{~g} / \mathrm{L}, 15.8 \%$ improvement) and molar yield (26.8\%, 32.0\% improvement) were achieved by strain CA1, of which the corresponding ALAS activity increased by $11 \%$ compared to the parent strain CA. When the intracellular ALAS activity further increased, growth inhibition was observed, accompanied by a decrease in 5-ALA production (Fig. 3a).

Based on the data obtained here, the correlation between ALAS activity and 5-ALA production was concluded (Fig. 3b). Although ALAS is a prerequisite for 5-ALA biosynthesis, its expression level is not as high as possible for the product formation. The ALAS activity in crude extract around $3.1 \mu \mathrm{mol} / \mathrm{L}$ min mostly favored 5-ALA production in C. glutamicum. The decreases in 5-ALA production level and biomass were possibly 


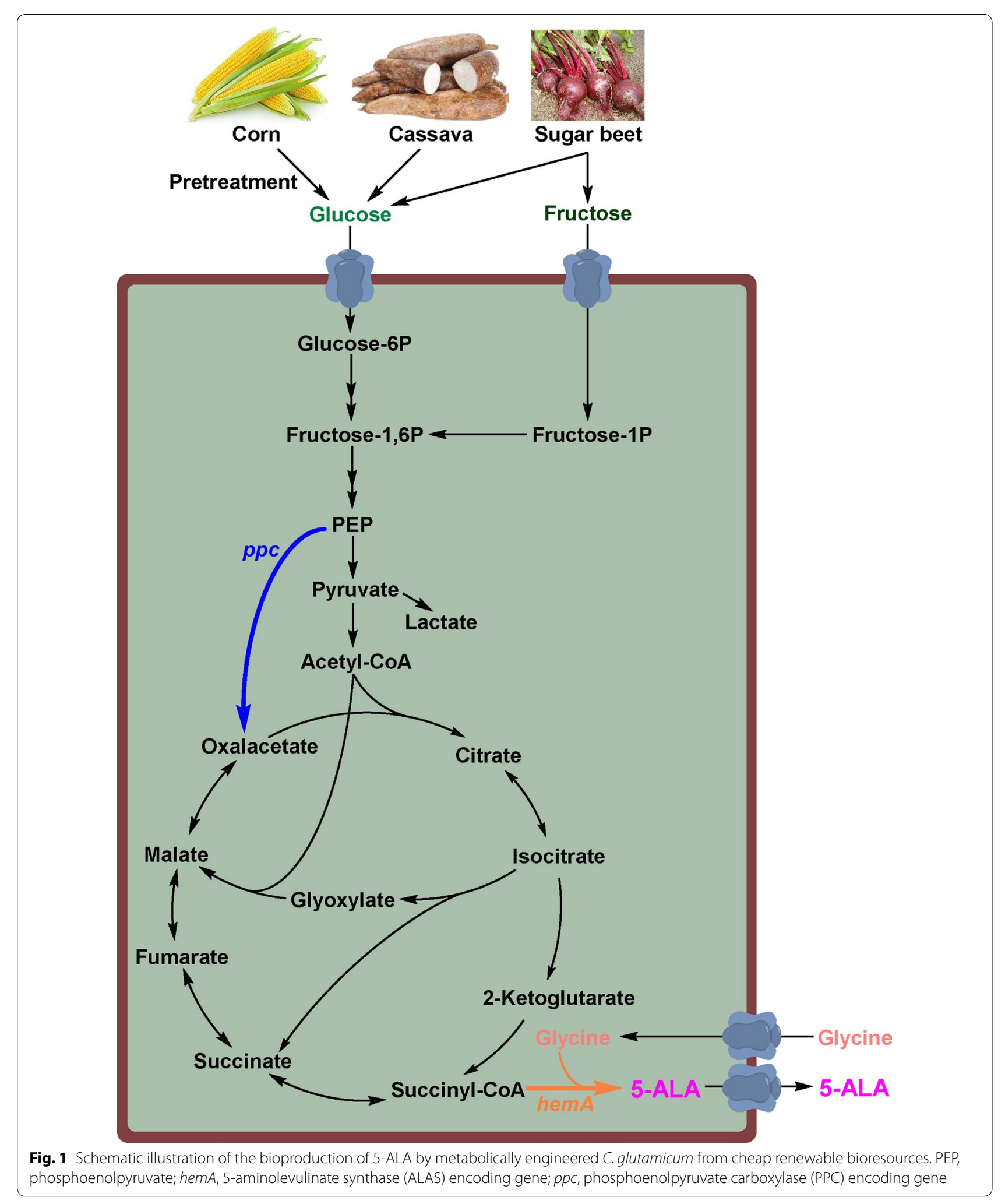




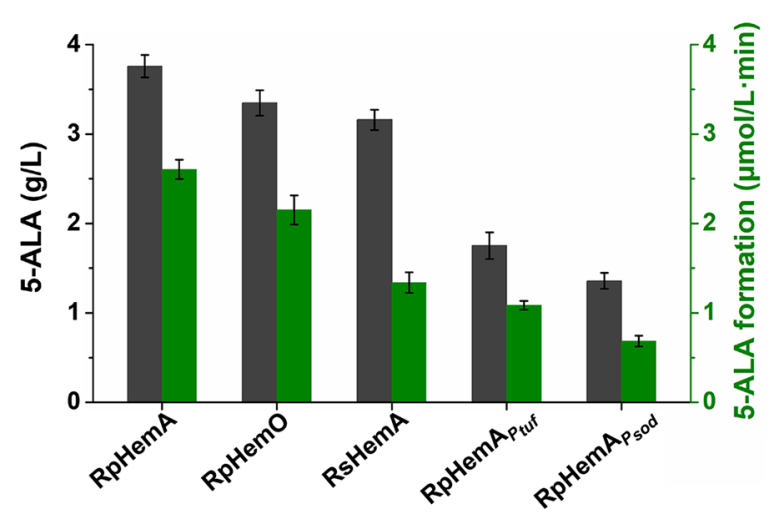

Fig. 2 Screening of ALASs from different sources for 5-ALA production. RpHemA, hemA from R. palustris, expressed using $P_{\text {trci }}$ RpHemO, hemO from R. palustris, expressed using $P_{t r i}$ Rs HemA, hemA from $R$. sphaeroides, expressed using $P_{\text {tri }}$ RpHemA $A_{\text {pturi }}$ hemA from $R$. palustris, expressed using $P_{\text {tufi }}$ RpHemA $A_{p_{s o d} \text { d }}$ hemA from R. palustris, expressed using $P_{\text {sod. }}$. Dark grey bars, 5-ALA production level; green bars, ALAS activity in crude extract. Strains with different ALASs were cultivated in shake flasks with modified M9 medium. The titer of 5-ALA at $36 \mathrm{~h}$ is shown. Cells were collected at the same time and lysed for ALAS activity assay. The reaction mixture contained $100 \mathrm{mM}$ Tris- $\mathrm{HCl}$ (pH 7.5), 200 mM glycine, 0.2 mM succinyl-CoA, $0.1 \mathrm{mM}$ pyridoxal phosphate (PLP) and $20 \mu \mathrm{g}$ crude extract. After proceeding at $37^{\circ} \mathrm{C}$ for $10 \mathrm{~min}$, the reaction was terminated by the addition of $10 \%(\mathrm{v} / \mathrm{v})$ trichloroacetic acid. Concentration of 5-ALA in the supernatant was determined. Error bars indicate standard deviations from three parallel experiments caused by the unbalanced 5-ALA biosynthetic pathway and TCA cycle. Succinyl-CoA, the precursor of 5-ALA biosynthesis, is also an intermediate of TCA cycle and plays an important role in a variety of metabolic processes [39]. The over-consumption of succinyl-CoA by excessive ALAS enzyme may slow down TCA cycle and affect energy metabolism, resulting in a tradeoff effect like growth inhibition observed here (Fig. 3a). Furthermore, production of large amounts of ALAS protein would require substantial resources, which would lay a heavy metabolic burden on cell maintenance and propagation. Thus, moderate expression of ALAS was optimal for maximizing 5-ALA production in C. glutamicum.

\section{Balancing 5-ALA biosynthetic pathway and anaplerotic pathway for enhanced 5-ALA production}

Considering 5-ALA biosynthesis withdraws carbon flux from TCA cycle, enhancement of the anaplerotic pathway for oxaloacetate should favor 5-ALA production. Overexpression of phosphoenolpyruvate carboxylase (PPC) has been proven to be effective to improve biosynthesis of oxaloacetate derivatives such as L-lysine, L-glutamate, and succinate [40-42]. Therefore, the native PPC of C. glutamicum was overexpressed under the control of the same $P_{t r c}$ promoter with ALAS in C. glutamicum strain CA1. The resultant strain CA1P exhibited a 46.3fold increase in intracellular PPC activity, demonstrating
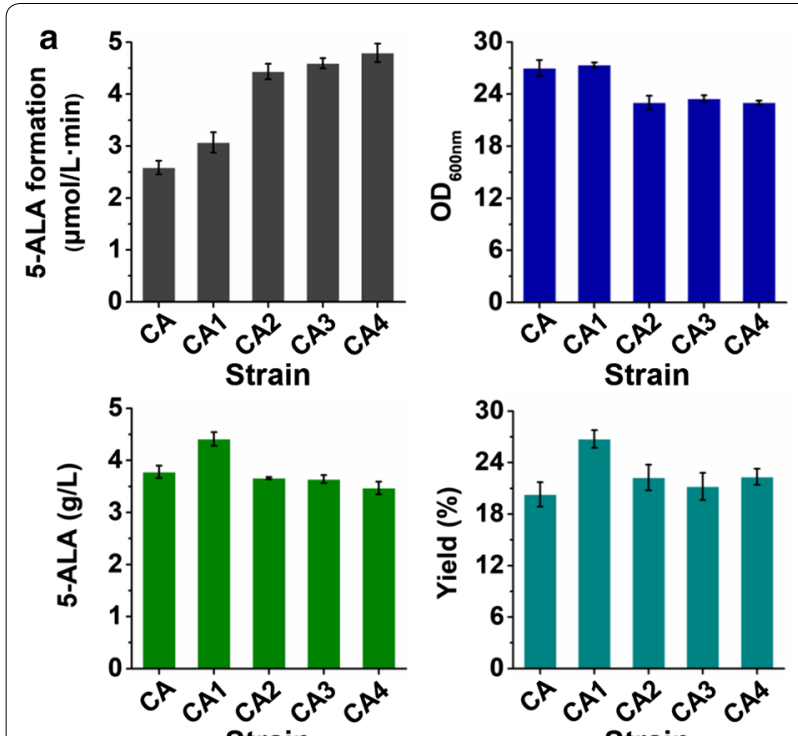

Strain

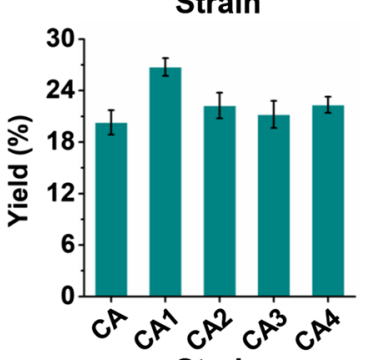

Strain

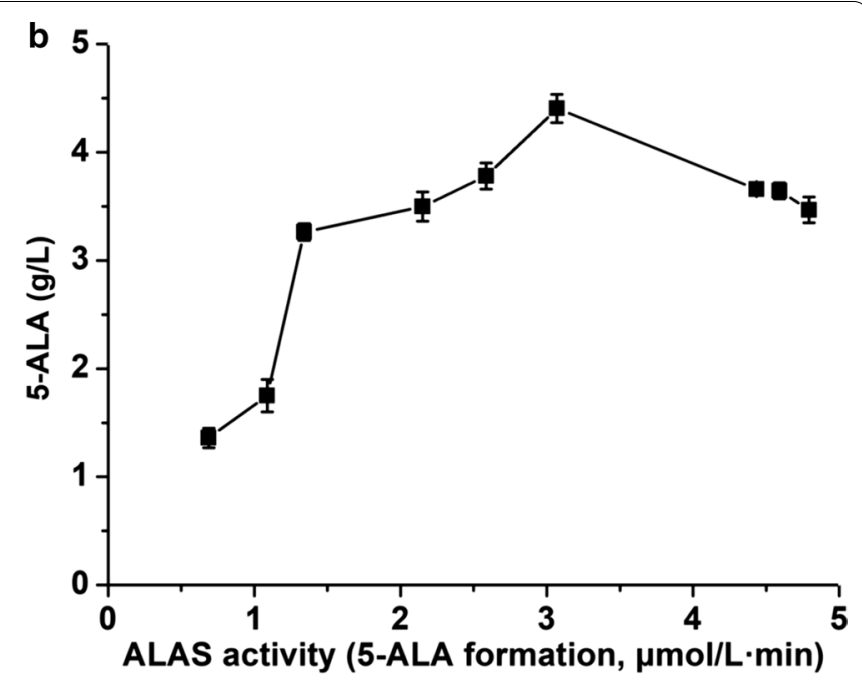

Fig. 3 Fine-tuning of ALAS expression for 5-ALA production. a Effects of regulating ALAS expression via RBS engineering on 5-ALA production. $\mathbf{b}$ Correlation between ALAS activity in crude extract and 5-ALA production level. The $x$-axis shows mean of ALAS activities in crude extract measured by ALAS formation rate of three parallel experiments. Strains were cultivated in shake flasks with modified M9 medium. OD $600 \mathrm{~nm}$ value, 5-ALA titer and yield at $36 \mathrm{~h}$ are shown. Cells were collected at the same time and lysed for ALAS activity assay. The reaction mixture contained $100 \mathrm{mM}$ Tris- $\mathrm{HCl}\left(\mathrm{pH}\right.$ 7.5), $200 \mathrm{mM}$ glycine, $0.2 \mathrm{mM}$ succinyl-CoA, $0.1 \mathrm{mM}$ pyridoxal phosphate (PLP) and $20 \mu \mathrm{g}$ crude extract. After proceeding at $37^{\circ} \mathrm{C}$ for $10 \mathrm{~min}$, the reaction was terminated by the addition of $10 \%(\mathrm{v} / \mathrm{V})$ trichloroacetic acid. Concentration of 5-ALA in the supernatant was determined. Error bars indicate standard deviations from three parallel experiments 
the successful overexpression. However, a slight decrease in 5-ALA titer was observed, which was possibly caused by the $26.3 \%$ decrease in intracellular ALAS activity (Figs. 3a, 4a). It has been reported that the expression levels of two proteins in a co-expression system are relatively lower than that of an individually expressed protein [43]. The results suggest that the excessive expression of PPC not only is unmatched with the cellular metabolism, but also competes with ALAS expression for resources.

To balance the 5-ALA biosynthetic pathway and anaplerotic pathway, PPC expression was optimized in strain CA1P using six RBSs with different translational activities (RBS-2, AAAGGAGGTTGTC; RBS-5, AAAGGAGTT GCTT; RBS-6, AAAGGAATTGGC; RBS-7, AAAGGT TTCAAGT; RBS-8, AAAGGCTGGAATT; RBS-9, AAA GGGTATTGGC) selected from reported RBS libraries [38]. Gradually decreased intracellular PPC activities were observed in engineered strains (Fig. 4a). Similar with the effect of regulating ALAS expression, 5-ALA production was first increased and then decreased along with the decrease in intracellular PPC activity. When the PPC activity in crude extract was $29.0 \mu \mathrm{mol} / \mathrm{L} \mathrm{min}$, the highest 5 -ALA titer $(5.5 \mathrm{~g} / \mathrm{L})$ was obtained by strain CA1P4 (Additional file 1: Fig. S1), which was increased by $34.1 \%$ compared with that of strain CA1P without
RBS optimization. Cell growth was also recovered due to the moderate expression of PPC (Fig. 4a). Based on the data obtained here, the correlation between intracellular PPC activity and 5-ALA production was also concluded (Fig. 4b). Obviously, a proper reinforcement of PPC activity is favorable for 5-ALA. The intracellular ALAS activity of strain CA1P4 was $2.9 \mu \mathrm{mol} / \mathrm{L}$ min, which was very close to that of strain CA1 $(3.1 \mu \mathrm{mol} / \mathrm{L}$ min) (Figs. 3a, 4a). This also suggests the balance between 5-ALA biosynthetic pathway and anaplerotic pathway is crucial for efficient 5-ALA production.

The strategy of strengthening the anaplerotic pathway for oxaloacetate has been applied for 5-ALA biosynthesis, but only limited improvement was achieved. Feng et al. replaced the native promoter of PPC with a strong promoter in a recombinant $C$. glutamicum strain expressing ALAS and this modification increased 5-ALA production by approximately $7.3 \%$. This encouraged the authors to further strengthen the anaplerotic pathway by overexpressing pyruvate carboxylase or deleting phosphoenolpyruvate carboxykinase, but these strategies failed to continuously enhance 5-ALA production [28]. In both the literatures and our cases, simply reinforcing the anaplerotic pathway has no positive and even negative effect on 5-ALA production. A finer tuning of expression of
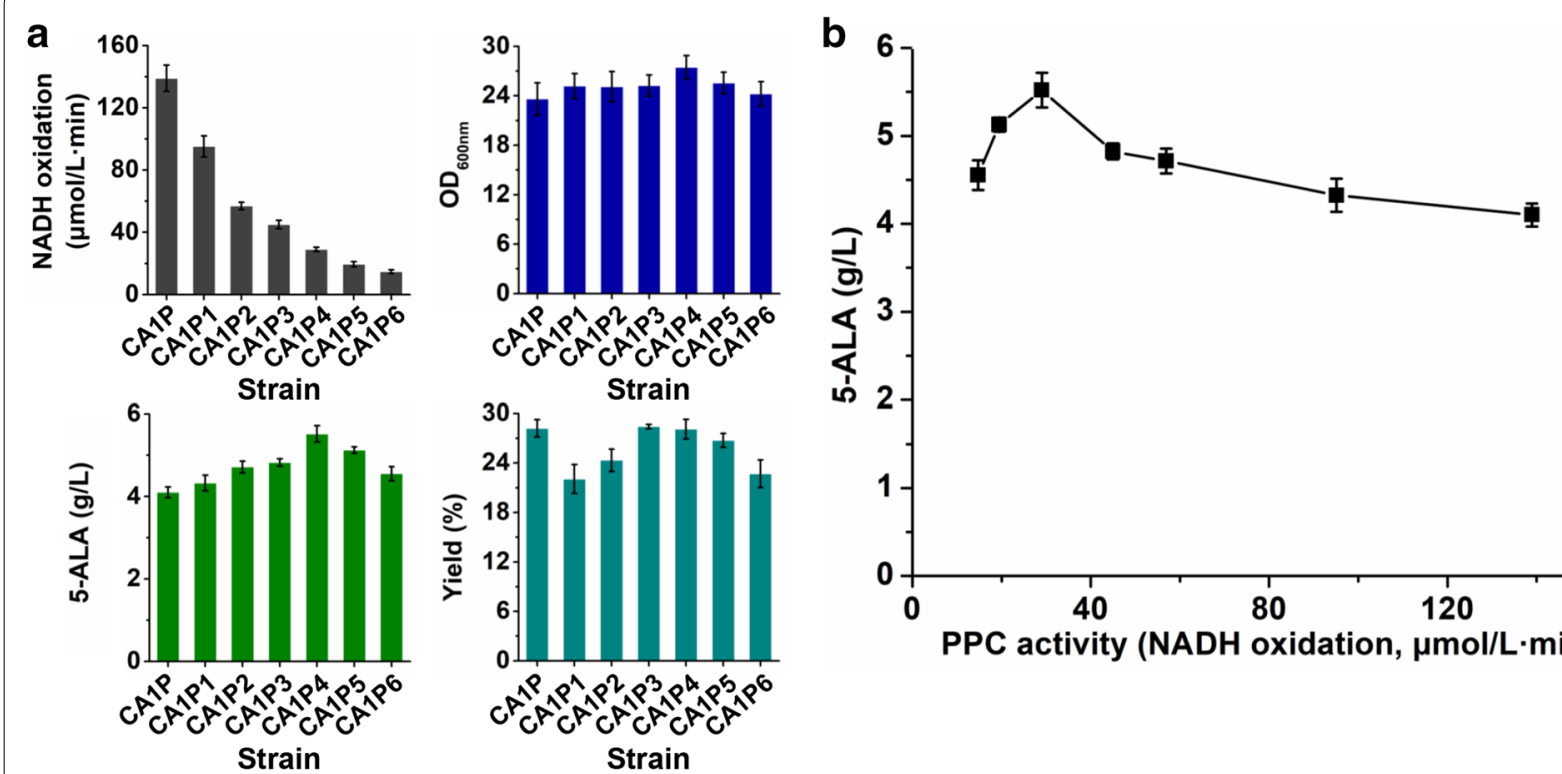

Fig. 4 Fine-tuning of PPC expression for 5-ALA production. a Effects of regulating PPC expression via RBS engineering on 5-ALA production. $\mathbf{b}$ Correlation between PPC activity in crude extract and 5-ALA production level. The $x$-axis shows mean of PPC activities in crude extract measured by NADH oxidation rate of three parallel experiments. Strains were cultivated in shake flasks with modified M9 medium. OD $600 \mathrm{~nm}$ value, 5-ALA titer and yield at $36 \mathrm{~h}$ are shown. Cells were collected at the same time and lysed for PPC activity assay. The PPC activity was determined by a coupling reaction catalyzed by malate dehydrogenase at $30^{\circ} \mathrm{C}$. The reaction mixture contained $100 \mathrm{mM}$ Tris- $\mathrm{HCl}(\mathrm{pH} 7.5), 2 \mathrm{mM}$ phosphoenolpyruvate, $10 \mathrm{mM} \mathrm{NaHCO}_{3}, 10 \mathrm{mM} \mathrm{MnSO}_{4}, 0.1 \mathrm{mM} \mathrm{NADH}, 20 \%$ (v/v) glycerol, $1.6 \mathrm{U}$ malate dehydrogenase, and $20 \mu \mathrm{g}$ crude extract. The activity was assayed spectrophotometrically by monitoring the decrease in absorbance of NADH at $340 \mathrm{~nm}$. Error bars indicate standard deviations from three parallel experiments 
key enzymes is strongly suggested to balance complicated pathways. Since biosynthesis of many target products derived from TCA cycle, such as succinic acid and $\gamma$-aminobutyric acid, can be potentially enhanced via strengthening the anaplerotic pathway for oxaloacetate $[44,45]$, the strategy presented here should be also useful for optimization of other bioproduction processes.

Fed-batch fermentation for 5-ALA production from glucose in 5-L bioreactors by C. glutamicum CA1P4

To test the high-level 5-ALA production potential of engineered strains, fed-batch fermentations were conducted in 5-L bioreactors using the optimized producer strain CA1P4 and the primary producer strain CA as a control. Overall, strain CA1P4 dramatically outmatched strain CA regarding cell growth, substrate uptake, 5-ALA production, and by-product formation (Fig. 5). Strain $\mathrm{CA}$ entered the stationary phage at $18 \mathrm{~h}$ with an $\mathrm{OD}_{600 \mathrm{~nm}}$ peak value of 98.9 , while strain CA1P4 had a prolonged exponential phage and increased the highest $\mathrm{OD}_{600 \mathrm{~nm}}$ by $11.4 \%$ to a value of 110.2 with $15.1 \%$ more glucose consumption. After $39 \mathrm{~h}$ fermentation, $16.3 \mathrm{~g} / \mathrm{L}$ of 5-ALA was produced by strain CA1P4, representing a 33.6\% improvement compared to strain CA (12.2 g/L) (Fig. 5). Lactate was the main by-product of this fermentation process and its formation also decreased from $2.5 \mathrm{~g} / \mathrm{L}$ for strain CA to $1.4 \mathrm{~g} / \mathrm{L}$ for strain CA1P4, without disruption of the lactate-forming pathway (Fig. 5). The results suggest that enhancing oxaloacetate replenishment by moderate PPC overexpression avoids excess accumulation of phosphoenolpyruvate and channels more carbon flux to 5-ALA biosynthesis. All these results suggested that optimizing the metabolic carbon flux by precise control of key enzyme activities is a highly effective strategy to improve 5-ALA production.

\section{Efficient 5-ALA production from cheap renewable bioresources}

Carbon sources often constitute a large portion of production cost in biological fermentation. Up to now, all the efforts to biologically produce 5-ALA use refined glucose as the main carbon source supplemented with a small amount of 5-ALA precursors such as succinate and glycine (Table 1). To reduce the cost of carbon source, it is desirable to explore alternative low-cost feedstocks with wide availability, such as agricultural residues and industrial wastes. We first selected an easy-to-handle feedstock with low impurity, corn starch, to replace refined glucose. $\alpha$-Amylase and glucoamylase were used for liquefaction and saccharification of corn starch prior to fermentation. The concentrated hydrolysate was then used to provide carbon source for 5-ALA production by strain CA1P4. Very similar growth, 5-ALA production, and byproduct formation were observed for fed-batch fermentation using corn starch hydrolysate and refined glucose. The final 5-ALA and lactate titers reached $16.0 \mathrm{~g} / \mathrm{L}$ and $1.1 \mathrm{~g} / \mathrm{L}$ in $39 \mathrm{~h}$, respectively (Fig. 6 and Additional file 1: Fig. S2).

Next, cassava bagasse, an agricultural residue from the industrial processing of cassava for starch extraction, was used for 5-ALA fermentation. Cassava bagasse is generated in large quantities in many countries and usually treated as a solid waste or a low-value animal feed. However, high residue contents of carbohydrate components in cassava bagasse can be converted to fermentable sugars. Given its low-cost, availability and
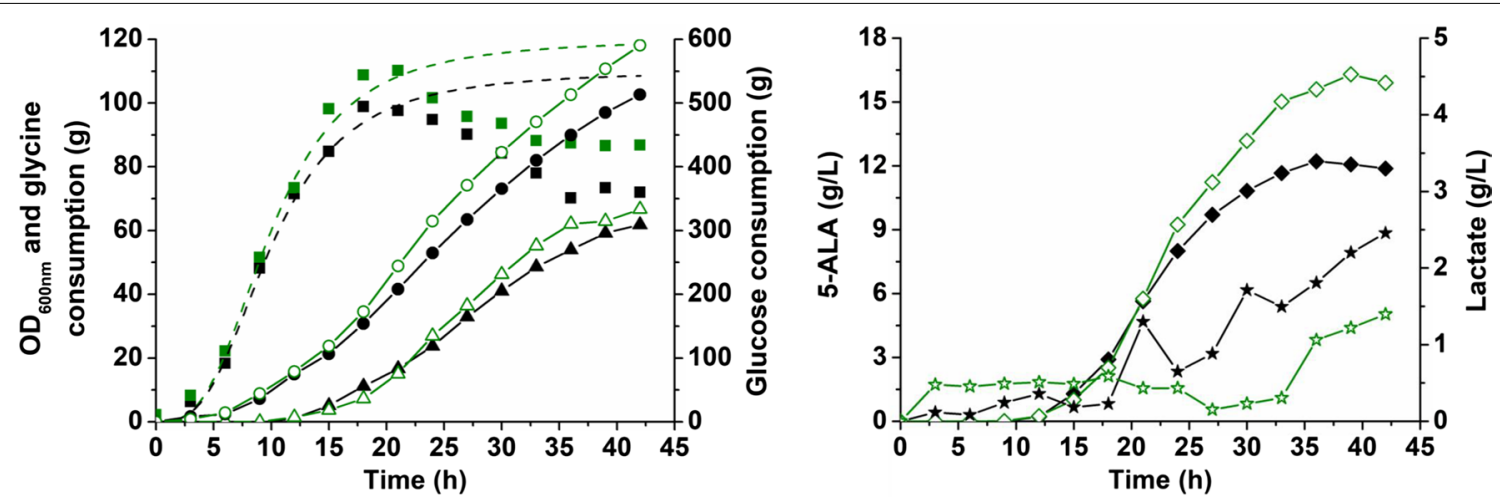

Fig. 5 Fed-batch fermentation for 5-ALA production from glucose using strains CA and CA1P4. Black filled labels represent strain CA and green open labels represent strain CA1P4. Square, $\mathrm{OD}_{600 \mathrm{~nm}}$; circle, glucose consumption; triangle, glycine consumption; diamond, 5-ALA; star, lactate. Dotted line represents simulated growth curve based on $\mathrm{OD}_{600 \mathrm{~nm}}$ data. Cultivation was performed in 5 - $\mathrm{L}$ bioreactors with fermentation medium. IPTG $(0.1 \mathrm{mM})$ and glycine $(4 \mathrm{~g} / \mathrm{L})$ were added when $\mathrm{OD}_{600 \mathrm{~nm}}$ reached approximately 40 to induce gene expression and 5-ALA biosynthesis. Glucose and glycine were continuously fed into the bioreactor during the fermentation. The pH was controlled at 6.5 initially and switched to 6.0 at $15 \mathrm{~h}$. The dissolved $\mathrm{O}_{2}$ was maintained at $30 \%$ initially and switched to $10 \%$ at $18 \mathrm{~h}$ 

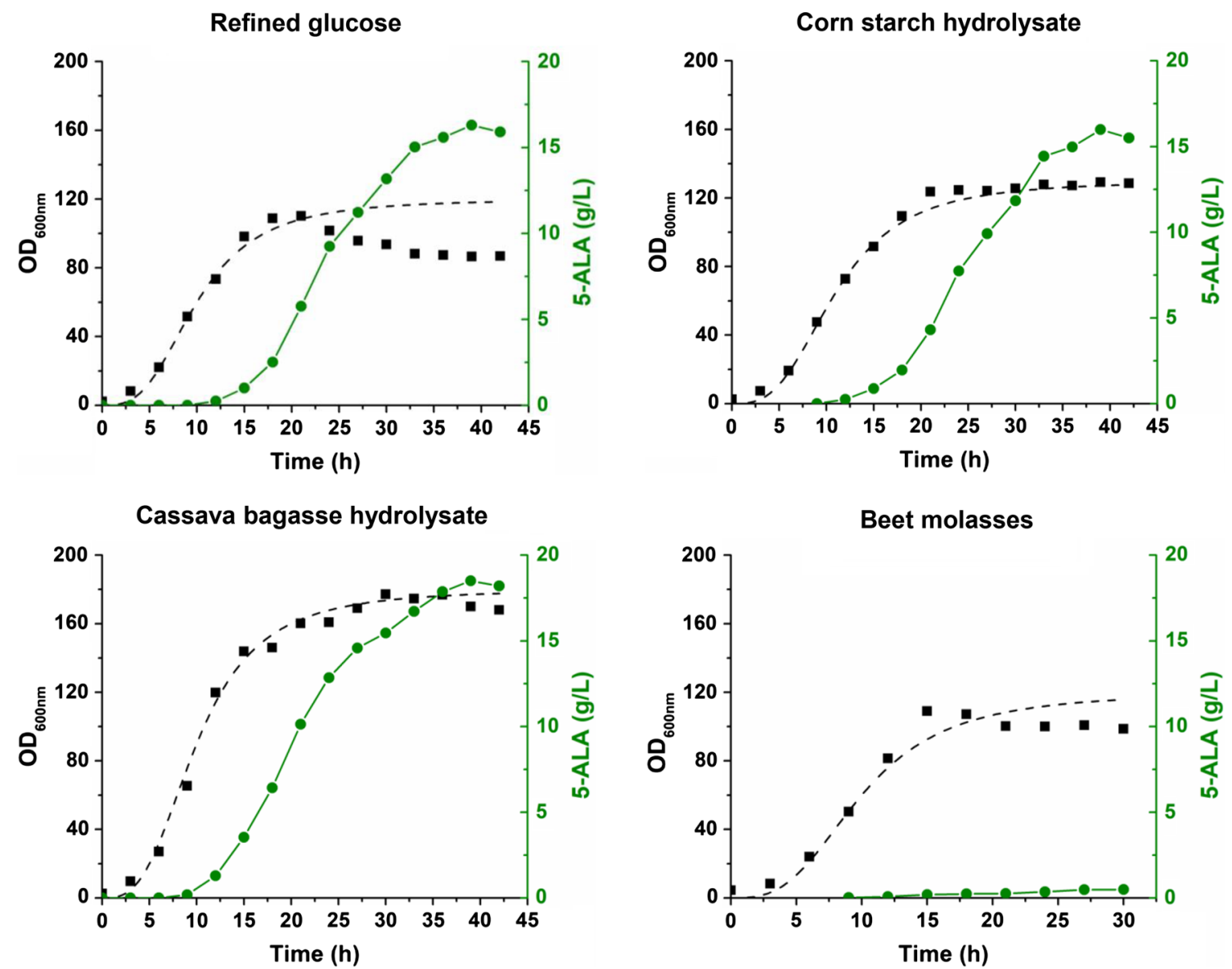

Fig. 6 Fed-batch fermentation for 5-ALA production using different carbon sources. Black square, OD $600 \mathrm{~nm}$; green circle, 5-ALA. Dotted line represents simulated growth curve based on $\mathrm{OD}_{600 \mathrm{~nm}}$ data. Cultivation was performed in 5-L bioreactors with fermentation medium. IPTG (0.1 mM) and glycine $(4 \mathrm{~g} / \mathrm{L})$ were added when $\mathrm{OD}_{600 \mathrm{~nm}}$ reached approximately 40 to induce gene expression and 5-ALA biosynthesis. Sugar solution and glycine were continuously fed into the bioreactor during the fermentation. The pH was controlled at 6.5 initially and switched to 6.0 at $15 \mathrm{~h}$. The dissolved $\mathrm{O}_{2}$ was maintained at $30 \%$ initially and switched to $10 \%$ at $18 \mathrm{~h}$

non-competition with food supply, cassava bagasse is an attractive feedstock for production of biofuels and biochemicals [46]. The cassava bagasse used in this study contains (w/w): $50.3 \%$ starch, $12.2 \%$ fiber (cellulose and hemicellulose), and $6.5 \%$ moisture. The carbohydrate components of the bagasse were mainly converted into sugars after enzymatic hydrolysis, with a yield of $0.53 \mathrm{~g}$ glucose/g cassava bagasse. Prior to fermentation, the hydrolysate was concentrated to a thick syrup containing approximately $420 \mathrm{~g} / \mathrm{L}$ glucose by evaporation under vacuum. After fed-batch fermentation, $18.5 \mathrm{~g} / \mathrm{L}$ 5-ALA was produced with a highest $\mathrm{OD}_{600 \mathrm{~nm}}$ value of 177.2 , which were $13.5 \%$ and $60.8 \%$ higher than those obtained by using refined glucose, respectively (Fig. 6). Lactate was the main by-product and its final titer $(1.2 \mathrm{~g} / \mathrm{L})$ was similar with those produced using refined glucose and corn starch hydrolysate (Additional file 1: Fig. S2).
Finally, beet molasses, the syrupy by-product yielded after sugar crystallization from sugar beet juice, was tested for 5-ALA production. Beet molasses is rich in sucrose and contains small amounts of glucose and fructose. To hydrolyze the sucrose and remove undesired compounds in beet molasses, a pretreatment procedure with sulfuric acid was conducted as previously described [47]. Use of beet molasses as the carbon source did not affect the cell growth, whereas 5-ALA was hardly produced during the fermentation. After $30 \mathrm{~h}$, the 5-ALA titer was only $0.5 \mathrm{~g} / \mathrm{L}$ in the fermentation broth (Fig. 6). Instead, large amounts of lactate $(7.1 \mathrm{~g} / \mathrm{L})$ and acetate $(4.9 \mathrm{~g} / \mathrm{L})$ were produced (Additional file 1: Fig. S2), suggesting a redistribution of metabolic flux possibly caused by certain effectors in beet molasses. It has been reported that beet molasses usually contains heavy metals such as iron, zinc, copper, manganese, magnesium, and calcium. High concentrations of heavy metals in the medium may 
inhibit activities of enzymes associated with biosynthesis [48]. Although sulfuric acid treatment is expected to remove some heavy metals, previous reports showed that contents of iron, zinc, copper, and nickel are not reduced by the pretreatment [49]. Notably, ALAS is sensitive to most of metal ions, such as iron, zinc, copper, plumbum, and cobalt [50]. Therefore, special pretreatment is required for removing heavy metals from beet molasses before it can be used for 5-ALA production.

Among the three tested cheap bioresources, cassava bagasse is obviously the most promising feedstock for 5-ALA production due to its beneficial effects on cell growth and 5-ALA formation. This result can be explained by the presence of some nutrients like vitamins and minerals in the hydrolysate [51]. The engineered strain CA1P4 with the best fermentation performance produced $18.5 \mathrm{~g} / \mathrm{L}$ 5-ALA using cassava bagasse hydrolysate. This titer is 1.6-fold higher than the previous record $(11.5 \mathrm{~g} / \mathrm{L})$ obtained by engineered $E$. coli using glucose as the main carbon source in a one-step fermentation process [32] (Table 1). Furthermore, this titer is even higher (1.3-fold) than that obtained in a two-step fermentation process $(14.7 \mathrm{~g} / \mathrm{L})$ [27]. Based on the fedbatch fermentation data, $9.4 \mathrm{~kg}$ glucose or $21.9 \mathrm{~kg}$ cassava bagasse would be cost for producing $1.0 \mathrm{~kg} 5$-ALA. Considering the price of cassava bagasse $(\sim 20 /$ ton $)$ is much lower than that of glucose $(\sim 521 /$ ton $)$, using cassava bagasse to replace glucose will reduce the cost of carbon source by $90.1 \%$.

\section{Conclusions}

In this study, we showed that 5-ALA production could be greatly enhanced by accurately regulating the expression of key enzymes involved in 5-ALA biosynthetic pathway and anaplerotic pathway in C. glutamicum. The best producer strain CA1P4 produced the highest 5-ALA titer up to $18.5 \mathrm{~g} / \mathrm{L}$ using cheap renewable bioresources including cassava bagasse in $39 \mathrm{~h}$ fermentation, which is the highest titer for 5-ALA bioproduction reported to date. The results bring a splendid expectation for large-scale bioproduction of 5-ALA. The metabolic engineering strategy presented here can be also applied to improve the bioproduction of other chemicals derived from TCA cycle.

\section{Methods}

\section{Bacterial strains and cultivation conditions}

The bacterial strains used in this study are listed in Table 2. E. coli DH5 $\alpha$ was used as the host for plasmid construction and was cultivated aerobically at $37{ }^{\circ} \mathrm{C}$ using Luria-Bertani (LB) medium. C. glutamicum ATCC 13032 and its derivatives were used for 5-ALA production and were cultivated aerobically at $30{ }^{\circ} \mathrm{C}$ in $\mathrm{LB}$ medium supplement with glucose. Kanamycin at a final concentration of $25 \mu \mathrm{g} / \mathrm{mL}$ or $50 \mu \mathrm{g} / \mathrm{mL}$ was added for $C$. glutamicum or E. coli as required, respectively.

For 5-ALA fermentation in shake flasks, the recombinant C. glutamicum strains were inoculated into $50 \mathrm{~mL}$ LB medium in 500-mL shake flasks containing $20 \mathrm{~g} / \mathrm{L}$ glucose and incubated at $30{ }^{\circ} \mathrm{C}$ and with shaking at $220 \mathrm{rpm}$ for $12 \mathrm{~h}$. The preculture was then inoculated into $50 \mathrm{~mL}$ modified M9 medium in $500 \mathrm{~mL}$ shake flasks to an initial $\mathrm{OD}_{600 \mathrm{~nm}}$ of 0.5 . Fermentation was performed at $30{ }^{\circ} \mathrm{C}$ and with shaking at $220 \mathrm{rpm}$, and the $\mathrm{pH}$ was maintained at $6.4-7.0$ with $25 \%$ ammonium hydroxide throughout the fermentation. IPTG was added to a final concentration of $0.1 \mathrm{mM}$ at $3 \mathrm{~h}$ to induce gene expression. The modified M9 medium contains $50 \mathrm{~g} / \mathrm{L}$ glucose, $17.1 \mathrm{~g} / \mathrm{L} \mathrm{Na}_{2} \mathrm{HPO}_{4} \cdot 12 \mathrm{H}_{2} \mathrm{O}, 6 \mathrm{~g} / \mathrm{L}$ glycine, $3 \mathrm{~g} / \mathrm{L} \mathrm{KH}_{2} \mathrm{PO}_{4}$, $2 \mathrm{~g} / \mathrm{L}$ yeast extract, $1 \mathrm{~g} / \mathrm{L} \mathrm{NH}_{4} \mathrm{Cl}, 0.5 \mathrm{~g} / \mathrm{L} \mathrm{NaCl}, 0.24 \mathrm{~g} / \mathrm{L}$ $\mathrm{MgSO}_{4} \cdot 7 \mathrm{H}_{2} \mathrm{O}$, and $11 \mathrm{mg} / \mathrm{L} \mathrm{CaCl}_{2}$.

For fed-batch fermentation in 5-L bioreactors, a 200$\mathrm{mL}$ seed culture cultivated using the seed medium for $12 \mathrm{~h}$ was transferred into a 5 - $\mathrm{L}$ bioreactor containing $2 \mathrm{~L}$ fermentation medium. Fermentation was conducted at $30{ }^{\circ} \mathrm{C}$ and with $30 \%$ dissolved oxygen (adjusted with aeration and agitation). After $18 \mathrm{~h}$ fermentation, the dissolved oxygen was maintained at $10 \%$. Initially, ammonium hydroxide was added automatically to maintain $\mathrm{pH}$ at 6.5 , and after $15 \mathrm{~h}$ fermentation the $\mathrm{pH}$ was maintained at 6.0. Glycine (final concentration of $4 \mathrm{~g} / \mathrm{L}$ ) and IPTG (final concentration of $0.1 \mathrm{mM}$ ) were added to induce gene expression and 5-ALA production when the $\mathrm{OD}_{600 \mathrm{~nm}}$ reached approximately 40. Sugar syrup containing $420 \mathrm{~g} / \mathrm{L}$ glucose or total sugar and $200 \mathrm{~g} / \mathrm{L}$ glycine solution were fed into the bioreactor to maintain the sugar and glycine concentrations at about $10 \mathrm{~g} / \mathrm{L}$ and $6 \mathrm{~g} / \mathrm{L}$, respectively. The seed medium contains $50 \mathrm{~g} / \mathrm{L}$ glucose, $5 \mathrm{~g} / \mathrm{L}$ yeast extract, $5 \mathrm{~g} / \mathrm{L}$ urea, $3 \mathrm{~g} / \mathrm{L} \mathrm{Na}_{2} \mathrm{HPO}_{4} \cdot 12 \mathrm{H}_{2} \mathrm{O}$, $3 \mathrm{~g} / \mathrm{L} \mathrm{KH}_{2} \mathrm{PO}_{4}, 1 \mathrm{~g} / \mathrm{L} \mathrm{NH}_{4} \mathrm{Cl}, 1 \mathrm{~g} / \mathrm{L} \mathrm{MgSO}{ }_{4} \cdot 7 \mathrm{H}_{2} \mathrm{O}, 0.5 \mathrm{~g} / \mathrm{L}$ $\mathrm{NaCl}, 20 \mathrm{mg} / \mathrm{L} \mathrm{MnSO}_{4} \cdot 5 \mathrm{H}_{2} \mathrm{O}, 11 \mathrm{mg} / \mathrm{L} \cdot \mathrm{CaCl}_{2}, 5 \mathrm{mg} / \mathrm{L}$ thiamine hydrochloride, and $0.1 \mathrm{mg} / \mathrm{L}$ biotin. The fermentation medium contains $50 \mathrm{~g} / \mathrm{L}$ initial sugar, $6 \mathrm{~g} / \mathrm{L}$ $\mathrm{K}_{2} \mathrm{HPO}_{4} \cdot 3 \mathrm{H}_{2} \mathrm{O}, 5 \mathrm{~g} / \mathrm{L} \mathrm{NH}_{4} \mathrm{Cl}, 2 \mathrm{~g} / \mathrm{L}$ yeast extract, $1.5 \mathrm{~g} / \mathrm{L}$ $\mathrm{KH}_{2} \mathrm{PO}_{4}, 1 \mathrm{~g} / \mathrm{L} \mathrm{MgSO}_{4} \cdot 7 \mathrm{H}_{2} \mathrm{O}, 0.5 \mathrm{~g} / \mathrm{L} \mathrm{NaCl}, 20 \mathrm{mg} / \mathrm{L}$ $\mathrm{MnSO}_{4} \cdot 5 \mathrm{H}_{2} \mathrm{O}, 11 \mathrm{mg} / \mathrm{L} \mathrm{CaCl}, 5 \mathrm{mg} / \mathrm{L}$ thiamine hydrochloride, and $0.1 \mathrm{mg} / \mathrm{L}$ biotin.

\section{Gene expression in C. glutamicum}

The E. coli-C. glutamicum shuttle vector pEC-XK99E was used for ALAS and PPC expression in C. glutamicum. All the recombinant plasmids constructed and used in this study are listed in Table 2. Plasmids pRpA, $\mathrm{pRpO}$, and pRsA were constructed by amplifying $\mathrm{RpHemA}$ and $\mathrm{RpHemO}$ encoding genes from $R$. palustris genomic DNA and RsHemA encoding gene from plasmid 
Table 2 Strains and plasmids used in this study

\begin{tabular}{|c|c|c|}
\hline Strain or plasmid & Description $^{a}$ & Reference or source \\
\hline \multicolumn{3}{|l|}{ Strain } \\
\hline E. coli DH5a & $\mathrm{F}^{-}$supE44 $\triangle$ lacU169 ( $\varphi 80$ lacZDM15) hsdR17 recA1 endA1 gyrA96 thi-1 relA1 & Invitrogen \\
\hline C. glutamicum ATCC 13032 & Wild type & ATCC \\
\hline CA & C. glutamicum ATCC 13032 derivative harboring plasmid pRpA & This study \\
\hline $\mathrm{CO}$ & C. glutamicum ATCC 13032 derivative harboring plasmid pRpO & This study \\
\hline CA-Rs & C. glutamicum ATCC 13032 derivative harboring plasmid pRsA & This study \\
\hline CA1 & C. glutamicum ATCC 13032 derivative harboring plasmid pRpA1 & This study \\
\hline CA2 & C. glutamicum ATCC 13032 derivative harboring plasmid pRpA2 & This study \\
\hline CA3 & C. glutamicum ATCC 13032 derivative harboring plasmid pRpA3 & This study \\
\hline CA4 & C. glutamicum ATCC 13032 derivative harboring plasmid pRpA4 & This study \\
\hline CA1P & C. glutamicum ATCC 13032 derivative harboring plasmid pRpA1P & This study \\
\hline CA1P1 & C. glutamicum ATCC 13032 derivative harboring plasmid pRpA1P1 & This study \\
\hline CA1P2 & C. glutamicum ATCC 13032 derivative harboring plasmid pRpA1P2 & This study \\
\hline CA1P3 & C. glutamicum ATCC 13032 derivative harboring plasmid pRpA1P3 & This study \\
\hline CA1P4 & C. glutamicum ATCC 13032 derivative harboring plasmid pRpA1P4 & This study \\
\hline CA1P5 & C. glutamicum ATCC 13032 derivative harboring plasmid pRpA1P5 & This study \\
\hline CA1P6 & C. glutamicum ATCC 13032 derivative harboring plasmid pRpA1P6 & This study \\
\hline \multicolumn{3}{|l|}{ Plasmid } \\
\hline pET28a-RS-hemA & pET28a harboring hemA from R. sphaeroides (RsHemA), Kan ${ }^{R}$ & {$[52]$} \\
\hline pEC-XK99E & E. coli-C. glutamicum shuttle vector, $P_{t r c}$ promoter, $\mathrm{Km}^{\mathrm{R}}$ & [58] \\
\hline $\mathrm{pRpA}$ & pEC-XK99E harboring hemA from R. palustris ATCC 17001 (RpHemA) & This study \\
\hline $\mathrm{pRpO}$ & pEC-XK99E harboring hemO from R. palustris ATCC 17001 (RpHemO) & This study \\
\hline pRsA & pEC-XK99E harboring hemA from R. sphaeroides (RsHemA) & This study \\
\hline pRpAtuf & $\begin{array}{l}\text { pRpA derivative, } P_{\text {trc }} \text { promoter of RpHemA replaced with } P_{\text {tuf }} \text { promoter of C. glutamicum ATCC } \\
13032\end{array}$ & This study \\
\hline pRpAsod & pRpA derivative, $P_{\text {trc }}$ promoter of RpHemA replaced with $P_{\text {sod }}$ of C. glutamicum ATCC 13032 & This study \\
\hline pRpA1 & pRpA derivative, RBS-1 of RpHemA replaced with RBS-2 & This study \\
\hline pRpA2 & pRpA derivative, RBS-1 of RpHemA replaced with RBS-3 & This study \\
\hline pRpA3 & pRpA derivative, RBS-1 of RpHemA replaced with RBS-4 & This study \\
\hline pRpA4 & pRpA derivative, RBS-1 of RpHemA replaced with RBS-5 & This study \\
\hline pRpA1P & pRpA1 derivative, harboring ppc from C. glutamicum ATCC 13032 & This study \\
\hline pRpA1P1 & pRpA1P derivative, RBS-1 of ppc replaced with RBS-2 & This study \\
\hline pRpA1P2 & pRpA1P derivative, RBS-1 of ppc replaced with RBS- 6 & This study \\
\hline pRpA1P3 & pRpA1P derivative, RBS-1 of $p p c$ replaced with RBS-7 & This study \\
\hline pRpA1P4 & pRpA1P derivative, RBS-1 of $p p c$ replaced with RBS-8 & This study \\
\hline pRpA1P5 & pRpA1P derivative, RBS-1 of $p p c$ replaced with RBS- 5 & This study \\
\hline pRpA1P6 & pRpA1P derivative, RBS-1 of $p p c$ replaced with RBS-9 & This study \\
\hline
\end{tabular}

${ }^{a} \mathrm{Kan}^{\mathrm{R}}$ represents resistance to kanamycin. RBSs used in this study are shown in Additional file 1: Table S2

pET28a-RS-hemA [52] using primers listed in Additional file 1: Table S1. The PCR products were then digested with EcoRI and SmaI and ligated with pEC-XK99E digested with the same endonucleases. For constitutive expression of RpHemA, constitutive promoters $P_{t u f}$ and $P_{\text {sod }}$ were amplified and cloned into $\mathrm{pRpA}$, resulting in plasmids pRpAsod and pRpAtuf, respectively. In order to optimize the expression of ALAS, the original RBS1 of ALAS gene in pRpA was replaced with four RBSs (see Additional file 1: Table S2) chosen from previously constructed libraries [38] by PCR, resulting in plasmids pRpA1-pRpA4. To overexpress PPC, $p p c$ gene with RBS1 was amplified from C. glutamicum ATCC 13032 genomic DNA and cloned into the SmaI and $\mathrm{XbaI}$ sites of plasmid pRpA1, resulting in plasmid pRpA1P. To regulate PPC expression, the original RBS1 of $p p c$ in plasmid pRpA1P was replaced with six RBSs (see Additional file 1: Table S2), resulting in pRpA1P1-pRpA1P6. The recombinant plasmids were transformed into $C$. glutamicum via electro-transformation. In the case of using $P_{t r c}$ to control 
gene expression, IPTG was added to a final concentration of $0.1 \mathrm{mM}$.

\section{Pretreatment of cheap bioresources}

Cassava bagasse, purchased from Qingdao Aisipurui Co., Ltd (Shandong, China), was dried and milled to a fine powder with a size about $50-100 \mu \mathrm{m}$. The cassava bagasse hydrolysate was prepared as described previously [53]. Briefly, $10 \%(\mathrm{w} / \mathrm{v})$ cassava bagasse mash was liquefied at $90{ }^{\circ} \mathrm{C}$ for $2 \mathrm{~h}$ using thermostable $\alpha$-amylase (Aladdin, Shanghai, China) with a dosage of $0.1 \%(w / w)$. Then, the liquefied mash that cooled to $60{ }^{\circ} \mathrm{C}$ was saccharified for $2 \mathrm{~h}$ using glucoamylase (Aladdin, Shanghai, China) with a dosage of $0.3 \%(\mathrm{w} / \mathrm{w})$. To hydrolyze the remaining cellulose, cellulase (Macklin, Shanghai, China) was added into the mixture at $0.4 \%(\mathrm{w} / \mathrm{w})$ for another $12 \mathrm{~h}$ treatment. After hydrolysis, the mixture was centrifuged at $7000 \mathrm{~g}$ for $15 \mathrm{~min}$ to remove the insoluble substances. The supernatant (cassava bagasse hydrolysate) was further concentrated by vacuum-rotary evaporation.

Corn starch was purchased from Shandong Xiwang Sugar Industry Co., Ltd. (Shandong, China) and its hydrolysate was prepared using the same liquefaction and saccharification processes with $\alpha$-amylase and glucoamylase as hydrolysis of cassava bagasse. After hydrolysis, the mixture was centrifuged at $7000 \mathrm{~g}$ for $15 \mathrm{~min}$ to remove the insoluble substances and concentrated by vacuum-rotary evaporation.

The beet molasses was provided by Neimenggu Fufeng Biotechnologies Co., Ltd (Neimenggu, China) and contained $53 \%(\mathrm{w} / \mathrm{w})$ sugars. The molasses was diluted with water at a 3:1 ratio to prepare a molasses solution. The acid treatment process entailed the addition of sulfuric acid to adjust the $\mathrm{pH}$ to 2.0 and subsequent incubation in a thermal bath at $100{ }^{\circ} \mathrm{C}$ for $30 \mathrm{~min}$. After incubation and cooling, the molasses solution was adjusted to $\mathrm{pH} 7.0$ using $1 \mathrm{M} \mathrm{NaOH}$ solution. Then the molasses solution was centrifuged at $7000 \mathrm{~g}$ for $15 \mathrm{~min}$ and the supernatant was used for fermentation [47].

\section{Enzyme activity assays}

Cells were collected and washed with $100 \mathrm{mM}$ Tris$\mathrm{HCl}$ buffer ( $\mathrm{pH}$ 7.5). Mechanical lysis of cells was performed with glass beads using FastPrep ${ }^{\circledR}-24$ Classic Instrument (MP Biomedicals, USA). The crude extract was centrifuged at $12,000 \mathrm{~g}$ for $10 \mathrm{~min}$ at $4{ }^{\circ} \mathrm{C}$, and the supernatant was used for enzyme activity assay. The protein concentration was determined with BCA Protein Assay Kit (Thermo Fisher Scientific, USA). ALAS activity was determined by measuring 5-ALA formation $(\mu \mathrm{mol} / \mathrm{L} \mathrm{min})[25]$. The reaction mixture contained $100 \mathrm{mM}$ Tris- $\mathrm{HCl}$ (pH 7.5), $200 \mathrm{mM}$ glycine, $0.2 \mathrm{mM}$ succinyl-CoA, $0.1 \mathrm{mM}$ pyridoxal phosphate (PLP) and
$20 \mu$ g crude extract. After proceeding at $37^{\circ} \mathrm{C}$ for $10 \mathrm{~min}$, the reaction was terminated by the addition of $10 \%(\mathrm{v} / \mathrm{v})$ trichloroacetic acid. Concentration of 5-ALA in the supernatant was determined. PPC activity was analyzed by a coupled reaction with malate dehydrogenase at $30{ }^{\circ} \mathrm{C}$ as previously described [54]. The reaction mixture contained $100 \mathrm{mM}$ Tris- $\mathrm{HCl}$ (pH 7.5), $2 \mathrm{mM}$ phosphoenolpyruvate, $10 \mathrm{mM} \mathrm{NaHCO}_{3}, 10 \mathrm{mM} \mathrm{MnSO}_{4}, 0.1 \mathrm{mM}$ $\mathrm{NADH}, 20 \%(\mathrm{v} / \mathrm{v})$ glycerol, $1.6 \mathrm{U}$ malate dehydrogenase, and $20 \mu \mathrm{g}$ crude extract. The activity was assayed spectrophotometrically by monitoring the decrease in absorbance of NADH at $340 \mathrm{~nm}$.

\section{Analytical methods}

Cell biomass was determined by the optical density at $600 \mathrm{~nm}\left(\mathrm{OD}_{600 \mathrm{~nm}}\right)$ with a UV-1800 spectrophotometer (Shimadzu, Kyoto, Japan) after proper dilution with distilled water. Glucose concentration was measured using SBA-40 (Biology Institute of Shandong Academy of Sciences, Shandong, China). The total sugar concentration was analyzed using the phenol/sulfuric acid method [55]. The concentration of 5-ALA in the fermentation broth was determined following the method described by Mauzerall and Granick [56]. Organic acids were analyzed by using HPLC equipped with a UV detector (Shimadzu, Japan) and a Bio-Rad Aminex HPX-87H column $(300 \times 7.8 \mathrm{~mm})$ according to the procedure described previously [57]. The 5-ALA yield was defined as (mole of 5 -ALA produced/mole of glucose consumed) $\times 100 \%$.

\section{Supplementary information}

\section{Supplementary information accompanies this paper at https://doi. org/10.1186/s13068-020-01685-0.}

Additional file 1: Figure S1. Plasmid pRpA1P4 used for hemA and $p p c$ overexpression in strain CA1P4. Figure S2. By-product lactate and acetate of fed-batch fermentations using different carbon sources. Table S1. Primers used in this study. Table S2. RBSs used in this study.

\section{Abbreviations}

5-ALA: 5-Aminolevulinic acid; ALAS: 5-ALA synthetase; IPTG: Isopropyl- $\beta$-Dthiogalactopyranoside; RBS: Ribosome binding site; PLP: Pyridoxal phosphate; PPC: Phosphoenolpyruvate carboxylase.

Acknowledgements

Not applicable.

Authors' contributions

JC, YW, PZ, JS, and YM conceptualized the project and designed the study. JC, YW, DR, and XG conducted the experiments and collected data. JC, YW, and WZ performed data analysis. JC, YW, PZ, JS, and YM composed the manuscript. $P Z$, JS, and YM provided critical feedback on the manuscript and provided resources. All authors read and approved the final manuscript.

Funding

This work was supported by the National Key R\&D Program of China [Grant Numbers 2018 YFA0900300 and 2018YFA0901400], the National Natural 
Science Foundation of China [Grant Numbers 31700044 and 31870044], and Key R\&D Plan of Shandong Province [Grant Number 2017CXGC1103].

\section{Availability of data and materials}

All data generated or analyzed in this study are included in this article and its Additional information files. The datasets used and/or analyzed during the current study are available from the corresponding author on reasonable request.

\section{Ethics approval and consent to participate}

Not applicable.

\section{Consent for publication}

Not applicable.

\section{Competing interests}

The authors declare that they have no competing interests.

Received: 14 November 2019 Accepted: 21 February 2020 Published online: 10 March 2020

\section{References}

1. Sasaki K, Watanabe M, Tanaka T. Biosynthesis, biotechnological production and applications of 5-aminolevulinic acid. Appl Microbiol Biotechnol. 2002:58:23-9.

2. Kang Z, Zhang JL, Zhou JW, Qi QS, Du GC, Chen J. Recent advances in microbial production of $\delta$-aminolevulinic acid and vitamin $B_{12}$. Biotechnol Adv. 2012:30:1533-42.

3. Inoue K. 5-Aminolevulinic acid-mediated photodynamic therapy for bladder cancer. Int J Urol. 2017:24:97-101.

4. Wu Y, Liao WB, Dawuda MM, Hu LL, Yu JH. 5-Aminolevulinic acid (ALA) biosynthetic and metabolic pathways and its role in higher plants: a review. Plant Growth Regul. 2019;87:357-74.

5. Chen YJ, Kim IH, Cho JH, Min BJ, Yoo JS, Wang Q. Effect of $\delta$-aminolevulinic acid on growth performance, nutrient digestibility, blood parameters and the immune response of weanling pigs challenged with Escherichia coli lipopolysaccharide. Livest Sci. 2008;114:108-16.

6. Sato K, Matsushita K, Takahashi K, Aoki M, Fuziwara J, Miyanari S, Kamada T. Dietary supplementation with 5-aminolevulinic acid modulates growth performance and inflammatory responses in broiler chickens. Poult Sci. 2012:91:1582-9.

7. Pedrosa-Gerasmio IR, Kondo H, Hirono I. Dietary 5-aminolevulinic acid enhances adenosine triphosphate production, ecdysis and immune response in Pacific white shrimp, Litopenaeus vannamei (Boone). Aquacult Res. 2019:50:1131-41.

8. Global 5-aminolevulinic acid hydrochloride market growth 2019-2024. https://www.360researchreports.com/global-5-aminolevulinic-acidhydrochloride-market-13902563. Accessed 30 Jan 2020.

9. Kang Z, Ding WW, Gong X, Liu QT, Du GC, Chen J. Recent advances in production of 5-aminolevulinic acid using biological strategies. World J Microbiol Biotechnol. 2017;33:200

10. Liu SL, Zhang GM, Li XK, Zhang J. Microbial production and applications of 5-aminolevulinic acid. Appl Microbiol Biotechnol. 2014;98:7349-57.

11. Nishikawa S, Watanabe K, Tanaka T, Miyachi N, Hotta Y, Murooka Y. Rhodobacter sphaeroides mutants which accumulate 5-aminolevulinic acid under aerobic and dark conditions. J Biosci Bioeng. 1999:87:798-804.

12. Sasaki K, Watanabe K, Tanaka T, Hotta Y, Nagai S. 5-Aminolevulinic acid production by Chlorella sp during heterotrophic cultivation in the dark. World J Microbiol Biotechnol. 1995;11:361-2.

13. Layer G, Reichelt J, Jahn D, Heinz DW. Structure and function of enzymes in heme biosynthesis. Protein Sci. 2010;19:1137-61.

14. Kang Z, Wang Y, Gu PF, Wang Q, Qi QS. Engineering Escherichia coli for efficient production of 5-aminolevulinic acid from glucose. Metab Eng. 2011;13:492-8.

15. Zhang JL, Kang Z, Chen J, Du GC. Optimization of the heme biosynthesis pathway for the production of 5-aminolevulinic acid in Escherichia coli. Sci Rep. 2015;5:8584.

16. Yu XL, Jin HY, Liu WJ, Wang Q, Qi QS. Engineering Corynebacterium glutamicum to produce 5-aminolevulinic acid from glucose. Microb Cell Fact. 2015;14:183.
17. Ramzi AB, Hyeon JE, Kim SW, Park C, Han SO. 5-Aminolevulinic acid production in engineered Corynebacterium glutamicum via C-5 biosynthesis pathway. Enzyme Microb Technol. 2015;81:1-7.

18. Noh MH, Lim HG, Park S, Seo SW, Jung GY. Precise flux redistribution to glyoxylate cycle for 5-aminolevulinic acid production in Escherichia coli. Metab Eng. 2017;43:1-8.

19. Zhang B, Ye BC. Pathway engineering in Corynebacterium glutamicum S9114 for 5-aminolevulinic acid production. 3 Biotech. 2018;8:247.

20. Zhang JL, Weng HJ, Zhou ZX, Du GC, Kang Z. Engineering of multiple modular pathways for high-yield production of 5-aminolevulinic acid in Escherichia coli. Bioresour Technol. 2019;274:353-60.

21. Xie L, Hall D, Eiteman MA, Altman E. Optimization of recombinant aminolevulinate synthase production in Escherichia coli using factorial design. Appl Microbiol Biotechnol. 2003;63:267-73.

22. Fu WQ, Lin HP, Cen PL. Enhancement of 5-aminolevulinate production with recombinant Escherichia coli using batch and fed-batch culture system. Bioresour Technol. 2008;99:4864-70.

23. Choi HP, Lee YM, Yun CW, Sung HC. Extracellular 5-aminolevulinic acid production by Escherichia coli containing the Rhodopseudomonas palustris KUGB306 hemA gene. J Microbiol Biotechnol. 2008;18:1136-40

24. Lin JP, Fu WQ, Cen PL. Characterization of 5-aminolevulinate synthase from Agrobacterium radiobacter, screening new inhibitors for 5-aminolevulinate dehydratase from Escherichia coli and their potential use for high 5-aminolevulinate production. Bioresour Technol. 2009;100:2293-7.

25. Zhang LL, Chen JZ, Chen N, Sun JB, Zheng P, Ma YH. Cloning of two 5-aminolevulinic acid synthase isozymes HemA and HemO from Rhodopseudomonas palustris with favorable characteristics for 5-aminolevulinic acid production. Biotechnol Lett. 2013;35:763-8.

26. Lou JW, Zhu L, Wu MB, Yang LR, Lin JP, Cen PL. High-level soluble expression of the hemA gene from Rhodobacter capsulatus and comparative study of its enzymatic properties. J Zhejiang Univ-SC B. 2014;15:491-9.

27. Yang P, Liu WJ, Cheng XL, Wang J, Wang Q, Qi QS. A new strategy for production of 5-aminolevulinic acid in recombinant Corynebacterium glutamicum with high yield. Appl Environ Microbiol. 2016;82:2709-17.

28. Feng LL, Zhang Y, Fu J, Mao YF, Chen T, Zhao XM, Wang ZW. Metabolic engineering of Corynebacterium glutamicum for efficient production of 5-aminolevulinic acid. Biotechnol Bioeng. 2016;113:1284-93.

29. Ding WW, Weng HJ, Du GC, Chen J, Kang Z. 5-Aminolevulinic acid production from inexpensive glucose by engineering the C4 pathway in Escherichia coli. J Ind Microbiol Biotechnol. 2017:44:1127-35.

30. Ren J, Zhou LB, Wang C, Lin C, Li ZD, Zeng AP. An unnatural pathway for efficient 5-aminolevulinic acid biosynthesis with glycine from glyoxylate based on retrobiosynthetic design. ACS Synth Biol. 2018;7:2750-7.

31. Zhou LB, Ren J, Li ZD, Nie JL, Wang C, Zeng AP. Characterization and engineering of a Clostridium glycine riboswitch and its use to control a novel metabolic pathway for 5-aminolevulinic acid production in Escherichia coli. ACS Synth Biol. 2019;8:2327-35.

32. Zhu CC, Chen JZ, Wang Y, Wang LX, Guo X, Chen N, Zheng P, Sun JB, Ma $\mathrm{YH}$. Enhancing 5-aminolevulinic acid tolerance and production by engineering the antioxidant defense system of Escherichia coli. Biotechnol Bioeng. 2019;116:2018-28.

33. Yang J, Zhu L, Fu WQ, Lin YJ, Lin JP, Cen PL. Improved 5-aminolevulinic acid production with recombinant Escherichia coli by a short-term dissolved oxygen shock in fed-batch fermentation. Chin J Chem Eng. 2013:21:1291-5.

34. Baritugo KAG, Kim HT, David YC, Choi JH, Choi Jl, Kim TW, Park C, Hong $\mathrm{SH}, \mathrm{Na}$ JG, Jeong KJ, Joo JC, Park SJ. Recent advances in metabolic engineering of Corynebacterium glutamicum as a potential platform microorganism for biorefinery. Biofuel Bioprod Bior. 2018;12:899-925.

35. Mao Y, Li G, Chang Z, Tao R, Cui Z, Wang Z, Tang YJ, Chen T, Zhao X. Metabolic engineering of Corynebacterium glutamicum for efficient production of succinate from lignocellulosic hydrolysate. Biotechnol Biofuels. 2018;11:95

36. Zhang Y, Liu D, Chen Z. Production of C2-C4 diols from renewable bioresources: new metabolic pathways and metabolic engineering strategies. Biotechnol Biofuels. 2017;10:299.

37. Shang X, Chai X, Lu X, Li Y, Zhang Y, Wang G, Zhang C, Liu S, Zhang Y, Ma J, Wen T. Native promoters of Corynebacterium glutamicum and its application in L-lysine production. Biotechnol Lett. 2018:40:383-91. 
38. Zhang B, Zhou N, Liu YM, Liu C, Lou CB, Jiang CY, Liu SJ. Ribosome binding site libraries and pathway modules for shikimic acid synthesis with Corynebacterium glutamicum. Microb Cell Fact. 2015;14:71.

39. Kind S, Becker J, Wittmann C. Increased lysine production by flux coupling of the tricarboxylic acid cycle and the lysine biosynthetic pathwaymetabolic engineering of the availability of succinyl-CoA in Corynebacterium glutamicum. Metab Eng. 2013;15:184-95.

40. Sauer U, Eikmanns BJ. The PEP-pyruvate-oxaloacetate node as the switch point for carbon flux distribution in bacteria. FEMS Microbiol Rev. 2005;29:765-94

41. Litsanov B, Kabus A, Brocker M, Bott M. Efficient aerobic succinate production from glucose in minimal medium with Corynebacterium glutamicum. Microb Biotechnol. 2012;5:116-28.

42. $\mathrm{Xu} \mathrm{Z,} \mathrm{Wu} \mathrm{ZH,} \mathrm{Gao} \mathrm{SJ,} \mathrm{Zhang} \mathrm{WG.} \mathrm{Rational} \mathrm{modification} \mathrm{of} \mathrm{tricarboxylic}$ acid cycle for improving L-lysine production in Corynebacterium glutamicum. Microb Cell Fact. 2018;17:105.

43. Wang Y, Li LX, Ma CQ, Gao C, Tao F, Xu P. Engineering of cofactor regeneration enhances (2S,3S)-2,3-butanediol production from diacetyl. Sci Rep. 2013;3:2643.

44. Zhang RZ, Yang TW, Rao ZM, Sun HM, Xu MJ, Zhang X, Xu ZH, Yang ST. Efficient one-step preparation of gamma-aminobutyric acid from glucose without an exogenous cofactor by the designed Corynebacterium glutamicum. Green Chem. 2014;16:4190-7.

45. Lin H, San KY, Bennett GN. Effect of Sorghum vulgare phosphoenolpyruvate carboxylase and Lactococcus lactis pyruvate carboxylase coexpression on succinate production in mutant strains of Escherichia coli. Appl Microbiol Biotechnol. 2005:67:515-23.

46. Zhang M, Xie L, Yin ZX, Khanal SK, Zhou Q. Biorefinery approach for cassava-based industrial wastes: current status and opportunities. Bioresour Technol. 2016;215:50-62.

47. Liu YP, Zheng P, Sun ZH, Ni Y, Dong JJ, Zhu LL. Economical succinic acid production from cane molasses by Actinobacillus succinogenes. Bioresour Technol. 2008;99:1736-42.

48. Roukas T. Pretreatment of beet molasses to increase pullulan production. Process Biochem. 1998;33:805-10.

49. Gojgic-Cvijovic GD, Jakovljevic DM, Loncarevic BD, Todorovic NM, Pergal MV, Ciric J, Loos K, Beskoski VP, Vrvic MM. Production of levan by Bacillus licheniformis NS032 in sugar beet molasses-based medium. Int J Biol Macromol. 2019;121:142-51.

50. Choi HP, Hong JW, Rhee KH, Sung HC. Cloning, expression, and characterization of 5-aminolevulinic acid synthase from Rhodopseudomonas palustris KUGB306. FEMS Microbiol Lett. 2004;236:175-81.

51. Thuy NTH, Kongkaew A, Flood A, Boontawan A. Fermentation and crystallization of succinic acid from Actinobacillus succinogenes ATCC55618 using fresh cassava root as the main substrate. Bioresour Technol. 2017;233:342-52.

52. Meng QL, Zhang YF, Ma CL, Ma HW, Zhao XM, Chen T. Purification and functional characterization of thermostable 5 -aminolevulinic acid synthases. Biotechnol Lett. 2015;37:2247-53.

53. Shi XC, Chen Y, Ren HF, Liu D, Zhao T, Zhao N, Ying HJ. Economically enhanced succinic acid fermentation from cassava bagasse hydrolysate using Corynebacterium glutamicum immobilized in porous polyurethane filler. Bioresour Technol. 2014;174:190-7.

54. Xu DY, Zhao J, Cao GQ, Wang JY, Li QG, Zheng P, Zhao SX, Sun JB. Removal of feedback inhibition of Corynebacterium glutamicum phosphoenolpyruvate carboxylase by addition of a short terminal peptide. Biotechnol Bioproc E. 2018;23:72-8.

55. Dubois M, Gilles KA, Hamilton JK, Rebers PA, Smith F. Colorimetric method for determination of sugars and related substances. Anal Chem. 1956;28:350-6

56. Mauzerall D, Granick S. The occurrence and determination of $\delta$-aminolevulinic acid and porphobilinogen in urine. J Biol Chem. 1956;219:435-46.

57. Tuyishime P, Wang Y, Fan LW, Zhang QQ, Li QG, Zheng P, Sun JB, Ma YH. Engineering Corynebacterium glutamicum for methanol-dependent growth and glutamate production. Metab Eng. 2018;49:220-31.

58. Kirchner $\mathrm{O}$, Tauch A. Tools for genetic engineering in the amino acidproducing bacterium Corynebacterium glutamicum. J Biotechnol. 2003;104:287-99.

\section{Publisher's Note}

Springer Nature remains neutral with regard to jurisdictional claims in published maps and institutional affiliations.
Ready to submit your research? Choose BMC and benefit from:

- fast, convenient online submission

- thorough peer review by experienced researchers in your field

- rapid publication on acceptance

- support for research data, including large and complex data types

- gold Open Access which fosters wider collaboration and increased citations

- maximum visibility for your research: over $100 \mathrm{M}$ website views per year

At $\mathrm{BMC}$, research is always in progress.

Learn more biomedcentral.com/submissions 